\title{
Hydrothermal Synthesis of Ag Thin Films and Their SERS Application
}

\author{
Nikolay P. Simonenko ${ }^{1, *}$, Andrey G. Musaev ${ }^{2}$, Tatiana L. Simonenko ${ }^{1}{ }^{\circledR}$, Philipp Yu. Gorobtsov ${ }^{1}$, \\ Ivan A. Volkov ${ }^{2}$, Alexander A. Gulin ${ }^{3}$, Elizaveta P. Simonenko ${ }^{1}$, Vladimir G. Sevastyanov ${ }^{1}$ \\ and Nikolay T. Kuznetsov ${ }^{1}$ \\ 1 Kurnakov Institute of General and Inorganic Chemistry of the Russian Academy of Sciences, 31 Leninsky pr., \\ 119991 Moscow, Russia; egorova.offver@gmail.com (T.L.S.); phigoros@gmail.com (P.Y.G.); \\ ep_simonenko@mail.ru (E.P.S.); vg_sevastyanov@mail.ru (V.G.S.); ntkuz@igic.ras.ru (N.T.K.) \\ 2 Moscow Institute of Physics and Technology, National Research University, 9 Institutskiy per., \\ 141701 Dolgoprudny, Russia; musaev.ag@mipt.ru (A.G.M.); volkov256@yandex.ru (I.A.V.) \\ 3 N.N. Semenov Federal Research Center for Chemical Physics of the Russian Academy of Sciences, \\ 4 Kosygina Street, Building 1, 119991 Moscow, Russia; aleksandr.gulin@phystech.edu \\ * Correspondence: n_simonenko@mail.ru
}

check for updates

Citation: Simonenko, N.P.; Musaev, A.G.; Simonenko, T.L.; Gorobtsov, P.Y.; Volkov, I.A.; Gulin, A.A.; Simonenko, E.P.; Sevastyanov, V.G.; Kuznetsov, N.T. Hydrothermal Synthesis of Ag Thin Films and Their SERS Application. Nanomaterials 2022, 12, 136. https://doi.org/ $10.3390 /$ nano12010136

Academic Editor: Dae Hong Jeong

Received: 7 December 2021

Accepted: 28 December 2021

Published: 31 December 2021

Publisher's Note: MDPI stays neutral with regard to jurisdictional claims in published maps and institutional affiliations.

Copyright: (C) 2021 by the authors. Licensee MDPI, Basel, Switzerland. This article is an open access article distributed under the terms and conditions of the Creative Commons Attribution (CC BY) license (https:// creativecommons.org/licenses/by/ $4.0 /)$.

\begin{abstract}
In this article, a facile, one-step method for the formation of silver thin-film nanostructures on the surface of $\mathrm{Al}_{2} \mathrm{O}_{3}$ substrates using the hydrothermal method is proposed. The dependence of the SERS effect intensity of the formed films during the detection of methylene blue (MB) low concentrations on the synthesis conditions, additional temperature treatment, and laser radiation wavelength (532 and $780 \mathrm{~nm}$ ) in comparison with similar dye films on commercial SERS substrates is shown. The detection limit of the analyte used for the indicated lasers is estimated. The effect of the synthesis temperature on the particle size, crystal structure, and microstructure features of the obtained thin films based on silver nanoparticles is demonstrated. Using spreading resistance microscopy, the interface between the substrate and Ag particles is studied, and the dependence of the size of the corresponding gap between them and the nature of microstructural defects on the parameters of hydrothermal treatment of reaction systems in the presence of $\mathrm{Al}_{2} \mathrm{O}_{3}$ substrates is shown. As a result of the study, the factors associated with the properties of the obtained SERS substrates and the parameters of recording the spectra, which affect the amplification factor of the spectral lines intensity of the analyte, are revealed.
\end{abstract}

Keywords: Ag film; silver nanoparticles; hydrothermal synthesis; surface-enhanced Raman spectroscopy; methylene blue

\section{Introduction}

As is known, surface-enhanced Raman spectroscopy (SERS) has proven to be an effective high-sensitivity method of chemical analysis since its discovery, as far as this approach makes it possible to amplify Raman signals by several orders of magnitude when implementing electromagnetic and chemical effects [1]. In this case, charge transfer between the adsorbed analyte molecules and the surface of metal particles occurs, as well as an amplification of the electromagnetic field with excitation of the localised plasmon resonance on the metal surface. Signal amplification occurs when analyte molecules are located in the spaces between neighbouring metal nanoparticles (so-called 'hot spots') [2]. SERS is used as a useful tool in various applications-analytical chemistry, atmospheric monitoring, safety control, biodetection, biomedicine, etc. [2,3].

As a rule, surface-enhanced Raman spectroscopy uses substrates whose surface is modified with silver, gold, or copper nanostructures with different microstructural characteristics [4-12]. Recently, much of researchers' attention has also been directed toward studying the processes of obtaining composite SERS-active films-Ag@nanoAu [4], Ag 
nanocubes@poly(dimethylsiloxane) [13], $\mathrm{Ag} / \mathrm{TiO}_{2}$ [14], $\mathrm{MoO}_{3-\mathrm{x}} / \mathrm{Ag}$ [15], b-cyclodextrinmodified $\mathrm{Ag}$ [16], $\mathrm{Au} / \mathrm{Ag}$ and $\mathrm{Au} / \mathrm{Ni}$ [7,17], Ag particles/Ag-Zr alloy [18], Mo-Ag [19], $\mathrm{Ag} / \mathrm{AgBr} / \mathrm{ZnO}$ [20], $\mathrm{ZnO} / \mathrm{Ag}$ 3D nanocomposites [21,22], $\mathrm{ZnO} / \mathrm{Au}$ [23], $\mathrm{MnO}_{2} / \mathrm{Au}$ [24], $\mathrm{Au} / \mathrm{ZrO}_{2}$ [25], rGO-Ag [26], or Ag/C [27]. In some cases, metal-free SERS substrates, particularly based on $\mathrm{MoS}_{2}$, are proposed [28]. Flexible substrates and membranes made of polymeric materials such as poly(dimethylsiloxane), polyimide, polyacrylonitrile, polyvinyl alcohol, etc. are also often used $[13,17-19,29,30]$. These nanostructures are obtained using a wide range of different methods-in situ formation at interfaces [31], thermal evaporation [32], solvent evaporation [33], one step galvanic displacement method which involves dipping [34], the Langmuir-Blodgett (LB) technique [35], convective assembly [36], chemical deposition [2,4,37], layer-by-layer assembly [38], vapor-phase deposition [5,39], spin casting [40], photochemical deposition [14,20]. Due to the wide variability and possibility to optimise different parameters, liquid-phase methods are the most convenient and simple for synthesising planar nanomaterials of different compositions of both metal and oxide [2,41-43]. Anisotropic and hierarchically organized SERS nanostructures are of particular interest today, since they often exhibit increased efficiency and selectivity for certain analytes $[2,6,7,13,30,39,44]$, and one of the most convenient approaches to the synthesis of such planar nanomaterials with an ordered microstructure is the hydrothermal method [45-51]. The main advantages of this method lie in the possibility to finely control the morphology of the formed materials, as well as in ensuring reproducibility, uniformity, and high adhesion of the grown coatings on substrates of different types. One of the dynamically developing and promising approaches to the formation of coatings with an ordered structure, including those based on metal nanoparticles, are printing technologies [52] that improve the targeted application of the material and the reproducibility of the process, which is very important in the fabrication of SERS-active nanostructures.

In this work, we proposed a simple, one-step method for obtaining thin-film Ag nanostructures on the surface of $\mathrm{Al}_{2} \mathrm{O}_{3}$ substrates using a hydrothermal method and found that they exhibit a more intense SERS signal, compared with commercial counterparts, when using methylene blue as an analyte and lasers with emission wavelengths of 532 and $780 \mathrm{~nm}$.

\section{Materials and Methods}

\subsection{Materials}

Silver nitrate $\left(\mathrm{AgNO}_{3}, 99.8 \%\right.$, Lenreactiv, Saint Petersburg, Russia), triethanolamine $\left(\mathrm{C}_{6} \mathrm{H}_{15} \mathrm{NO}_{3}, 99 \%\right.$, Chimmed, Moscow, Russia), acetic acid $\left(\mathrm{C}_{2} \mathrm{H}_{4} \mathrm{O}_{2}, 70 \%\right.$ aqueous solution, Lenreactiv, Saint Petersburg, Russia), 2-propanol $\left(\mathrm{C}_{3} \mathrm{H}_{8} \mathrm{O}, 99.8 \%\right.$, Ekos-1, Moscow, Russia), and 2-butanol $\left(\mathrm{C}_{4} \mathrm{H}_{10} \mathrm{O}, 99 \%\right.$, Ekos-1, Moscow, Russia) were used as reagents in this study. $\mathrm{Ag}$ films were applied to the surface of $\mathrm{Al}_{2} \mathrm{O}_{3}$ substrates (VK-100, 99.6\% $\mathrm{Al}_{2} \mathrm{O}_{3}$ content, C-Component, Moscow, Russia). When studying the intensity of SERS signals from the surface of hydrothermally grown Ag films, commercial analogs (Silver substrate 'Randa S', SERS-AG-35-1, Ato ID, Vilnius, Lithuania) were used for comparison. Methylene blue dye was used as an analyte in the SERS measurements.

\subsection{Hydrothermal Synthesis of Ag Thin Films}

Ag films were grown according to the scheme shown in Figure 1. The precursor solution in a typical experiment was prepared by dissolving $0.250 \mathrm{~g}$ of silver nitrate in $20 \mathrm{~mL}$ of distilled water, after which $1.280 \mathrm{~g}$ of triethanolamine was added under stirring, resulting in precipitation. Next, $0.4 \mathrm{~mL}$ of acetic acid solution was added to the reaction system until the precipitate dissolved completely, followed by $20 \mathrm{~mL}$ of 2-propanol addition. The concentration of silver cations (about $0.035 \mathrm{~mol} / \mathrm{L}$ ) and the content of other components in the reaction system were chosen to prevent an excessive rate of silver particle formation and immoderate amounts of solid phase formed. From the obtained solution of silver heteroligand complexes, an aliquot $(10 \mathrm{~mL})$ was taken and placed in a steel autoclave with a Teflon liner (a total vessel volume of $25 \mathrm{~mL}$ ) where two pre-cleaned and degreased $\mathrm{Al}_{2} \mathrm{O}_{3}$ substrates were mounted vertically. The autoclave was then hermetically sealed and 
subjected to heating in a muffle furnace to 100,120 , and $140^{\circ} \mathrm{C}$ at a rate of $5^{\circ} / \mathrm{min}$, after which it was kept at a given temperature for $1 \mathrm{~h}$ and then naturally cooled to $25^{\circ} \mathrm{C}$ along with the furnace. The heat treatment initiated the reduction of silver cations and the growth of metal nanoparticles on the surface of ceramic substrates. After cooling the reaction systems and extracting the substrates with the applied Ag films, the formed materials were washed with distilled water and 2-propanol, followed by drying at $50{ }^{\circ} \mathrm{C}$ for $2 \mathrm{~h}$. For SERS measurements, the samples were additionally heat-treated at $100{ }^{\circ} \mathrm{C}$ to minimise the amount of residual organic components on their surface.

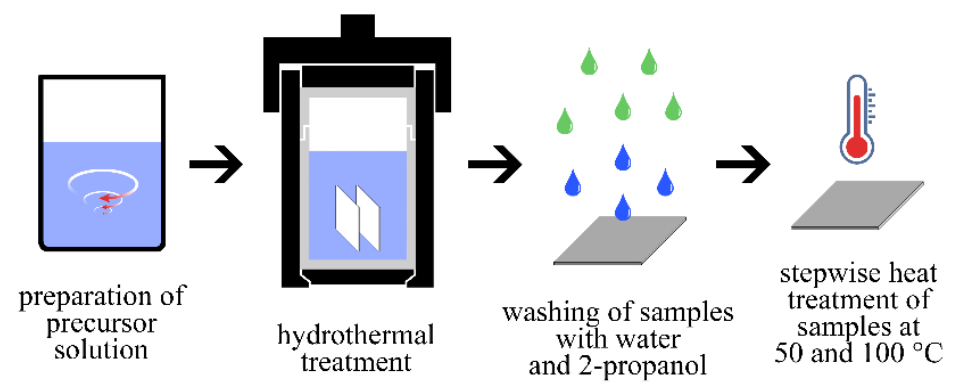

Figure 1. Scheme of the experiment.

\subsection{Application of Analyte Solutions to Substrates}

The obtained films consisting of silver nanoparticles were investigated for the possibility of surface-enhanced Raman scattering using methylene blue as a test analyte. For this purpose, solutions with concentrations of this compound $10^{-4}, 10^{-5}$, and $10^{-6} \mathrm{~mol} / \mathrm{L}$ were prepared. A 4:1 mixture of 2-butanol and distilled water was used as a solvent. To detect the SERS effect and find the factors affecting the spectral line intensity gain, $0.1 \mu \mathrm{L}$ solutions of the analyte with the concentration of $10^{-4} \mathrm{~mol} / \mathrm{L}$ were applied to the samples of investigated coatings and ceramic substrate of aluminium oxide using a pipette dispenser. To evaluate the detection limit achieved through the SERS effect, solutions with a concentration of methylene blue $10^{-4}, 10^{-5}$, and $10^{-6} \mathrm{~mol} / \mathrm{L}$ were applied to the coating samples in a similar manner. The solvent contained in the solutions was then completely evaporated for $10 \mathrm{~min}$, resulting in the formation of a solid phase of the analyte distributed in the structure of the metal coating.

\subsection{Instrumentation}

The thermal behaviour of the precursor solution was analysed using a combined DSC/DTA/TG analyser SDT-Q600 (TA Instruments, New Castle, DE, USA) in $\mathrm{Al}_{2} \mathrm{O}_{3}$ micro crucible (airflow $250 \mathrm{~mL} / \mathrm{min}$; sample weight $44 \mathrm{mg}$; 1st step-heating to $100{ }^{\circ} \mathrm{C}, 10^{\circ} / \mathrm{min}$, holding at $100{ }^{\circ} \mathrm{C}$ for $15 \mathrm{~min}$; 2nd step-heating to $1000^{\circ} \mathrm{C}, 10^{\circ} / \mathrm{min}$ ).

X-ray diffraction analysis of the obtained films and the used $\mathrm{Al}_{2} \mathrm{O}_{3}$ substrates was performed on a D8-Advance diffractometer in the range of $2 \theta$ 20-80 (Bruker, Bremen, Germany, $\mathrm{CuK} \alpha=1.5418 \AA$, Ni-filter, $\mathrm{E}=40 \mathrm{keV}, \mathrm{I}=40 \mathrm{~mA}$, integration time $=0.3 \mathrm{~s} /$ point, step $=0.02^{\circ}$ ). Analysis of the XRD spectra was carried out with the use of the Rietveld refinement method, implemented in X'Pert HighScore Plus software (PANalytical B.V., Almelo, The Netherlands).

The microstructure of as-grown Ag films was studied by scanning electron microscopy (Carl Zeiss NVision 40, Oberkochen, Germany) using secondary and backscattered electron detectors (accelerating voltage was $1 \mathrm{kV}$ ).

The surface of the obtained films was also studied by atomic force microscopy (AFM). As a result, data on the microstructure of the film surface as well as local electrophysical properties (electron work function and current-voltage curves) were obtained. These studies were performed on a Solver Pro-M scanning probe microscope (NT-MDT LLC, Zelenograd, Russia) in ambient conditions in semi-contact AFM, Kelvin probe force microscopy (KPSM) using ETALON HA-HR probes with a conductive coating based on $\mathrm{W}_{2} \mathrm{C}$ (resonance frequency $\sim 366 \mathrm{kHz}$, spherical radius $<35 \mathrm{~nm}$ ) and in contact AFM and scanning 
spreading resistance microscopy modes using ETALON HA-C probes with a $\mathrm{W}_{2} \mathrm{C}$-based conductive coating (force constant $\sim 0.26 \mathrm{~N} / \mathrm{m}$, spherical radius $<35 \mathrm{~nm}$ ). Grounding of the samples for measurements in the KPFM mode and applying a voltage to it for spreading resistance imaging was carried out as described in another study [53].

Raman spectroscopy was performed using a DXR Raman microscope (Thermo Fisher, Waltham, MA, USA). To work with the samples, a 10× objective was used, since it allowed the greatest reduction in the energy density of laser radiation falling on the investigated area. This made it possible to reduce the destruction of chemical bonds of the dye, which helped to slow down the reduction in the signal during measurements. Laser power, aperture width, exposure duration, and the number of shots were selected in such a way as to obtain the best signal amplification and signal-to-noise ratio. For a laser with a radiation wavelength of $532 \mathrm{~nm}$, the power was $1 \mathrm{~mW}$, the aperture was $25 \mathrm{mkm}$ pinhole, the number of shots was 20, and the exposure was $1 \mathrm{~s}$. For the $780 \mathrm{~nm}$ laser, the power was $20 \mathrm{~mW}$, the aperture was $25 \mathrm{mkm}$ pinhole, the number of shots was 30, and the exposure was $2 \mathrm{~s}$. During the recording of the spectra, the result for all images was automatically averaged, and processing was immediately carried out to reduce the influence of fluorescence on the measurement result.

\section{Results and Discussion}

\subsection{Characterisation of the Precursor Solution}

The precursor solution used for the hydrothermal synthesis of Ag films was studied using synchronous thermal analysis under stage heating. In the first step (heating to $100{ }^{\circ} \mathrm{C}$ and holding at this temperature for $15 \mathrm{~min}$ ), weight loss due to solvent evaporation was $83 \%$. At further heating (Figure 2) there was a two-step weight loss-in the temperature intervals $100-230{ }^{\circ} \mathrm{C}(80.3 \%)$ and $230-400{ }^{\circ} \mathrm{C}(7.8 \%)$. During further heating, the change in the sample weight was insignificant, indicating complete removal of liquid components and decomposition of precursors up to $400{ }^{\circ} \mathrm{C}$. In this case, the total weight loss of ink during heating in the temperature range of $25-400{ }^{\circ} \mathrm{C}$ was $99.49 \%$. Thus, heat treatment of precursor solution film, applied to any substrate, can allow obtaining metal coatings, but at atmospheric pressure, in order to avoid admixture of organic components, heat treatment should be carried out in oxidising atmosphere at temperatures of about $350-400{ }^{\circ} \mathrm{C}$, which can lead to significant coarsening of silver particles. The use of this precursor solution for the growth of Ag films under hydrothermal conditions can lead to a substantial reduction in the synthesis temperature while minimising the number of organic impurities in metal coatings and increasing the dispersity of the silver particles composing them.

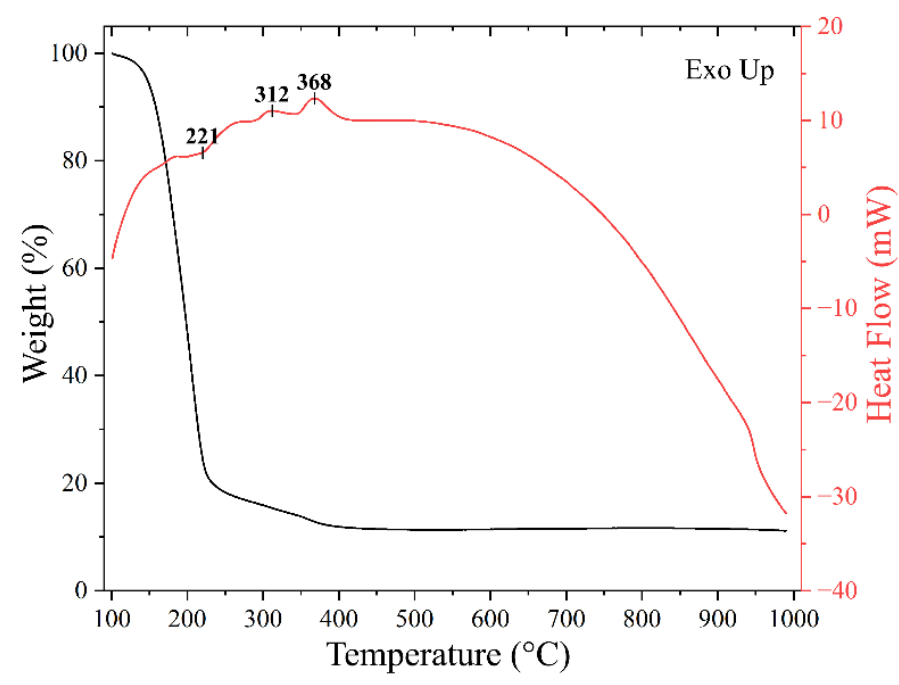

Figure 2. TGA and DSC curves for the precursor solution when heated in an air current in the temperature range $100-1000{ }^{\circ} \mathrm{C}$. 


\subsection{Crystal Structure of As-Grown Ag Films}

As can be seen from X-ray diffraction patterns (Figure 3) of metal films grown in hydrothermal conditions on the surface of $\mathrm{Al}_{2} \mathrm{O}_{3}$ substrates under various conditions, in all cases, silver coatings were formed, having a characteristic set of reflexes corresponding to the cubic crystal lattice (space group Fm-3m), which agrees well with the literature data (PDF \#87-0717). Sufficiently high intensity of reflexes of the substrate material $\left(\mathrm{Al}_{2} \mathrm{O}_{3}\right.$, rhombohedral crystal lattice, space group R-3c, PDF \#71-1126) indicates a thin-film structure of the formed Ag films. Full-profile analysis of patterns made it possible to estimate the average size of the coherent scattering region (CSR) of silver particles composing the films, which was $70 \pm 7,86 \pm 8$, and $81 \pm 8 \mathrm{~nm}$ at synthesis temperatures of 100,120 , and $140{ }^{\circ} \mathrm{C}$, respectively. As can be seen, the dependence of the average CSR size on the synthesis temperature had an extreme nature, and the most highly dispersed film, according to XRD, was formed at a temperature of hydrothermal treatment of $100{ }^{\circ} \mathrm{C}$. The calculated values of the crystal lattice parameters also had extreme dependence on the synthesis temperature $\left(100{ }^{\circ} \mathrm{C}: \mathrm{a}=\mathrm{b}=\mathrm{c}=4.088(1) \AA, 120^{\circ} \mathrm{C}: \mathrm{a}=4.089(1) \AA, 140{ }^{\circ} \mathrm{C}: \mathrm{a}=4.088(1) \AA\right)$. The results also indicate that the grown $\mathrm{Ag}$ films did not contain any crystalline impurities (reagents, precursors, or by-products).

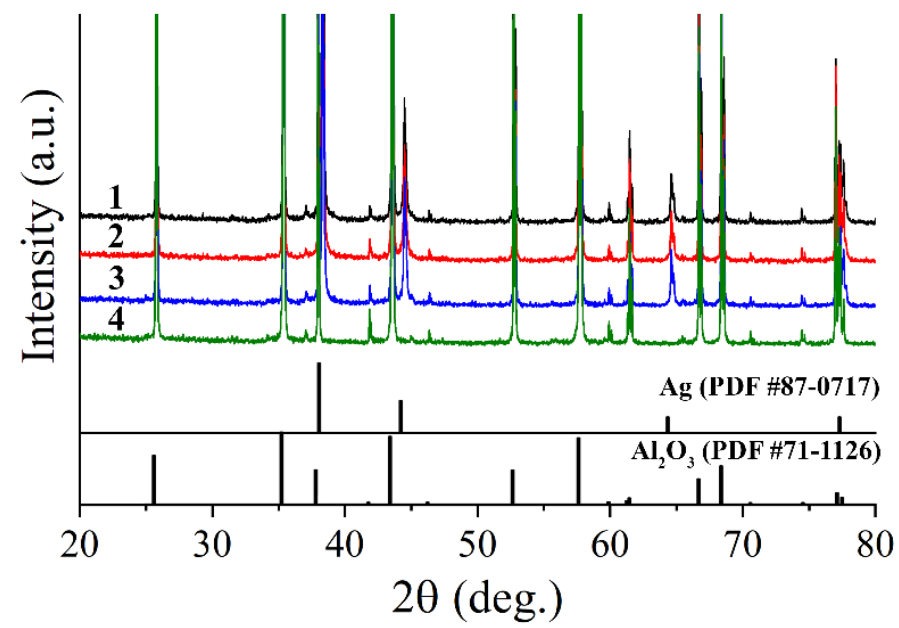

Figure 3. X-ray diffraction patterns of $\mathrm{Ag}$ films grown on the surface of $\mathrm{Al}_{2} \mathrm{O}_{3}$ substrates at different temperatures $\left(1-100,2-120,3-140{ }^{\circ} \mathrm{C}\right)$ as well as a diffractogram of the original $\mathrm{Al}_{2} \mathrm{O}_{3}$ substrate (4).

\subsection{Microstructure of the Studied Ag Films}

The microstructure of the Ag films grown under hydrothermal conditions was studied by scanning electron microscopy. As can be seen from the micrographs of the obtained metal films (Figure 4), they consist of particles with a bimodal size distribution. The average size of both small $(100 \rightarrow 110 \rightarrow 130 \mathrm{~nm})$ and large particles $(620 \rightarrow 700 \rightarrow 1350 \mathrm{~nm})$ increased with increasing synthesis temperature $\left(100 \rightarrow 120 \rightarrow 140{ }^{\circ} \mathrm{C}\right)$. According to the backscattered electron detector data, gaps between silver particles were well observed, the average size of which increased significantly $(30 \rightarrow 40 \rightarrow 80 \mathrm{~nm})$ as the hydrothermal treatment temperature increased. As can be seen, when increasing the synthesis temperature from 120 to $140{ }^{\circ} \mathrm{C}$, there was a sharp (twofold) jump in the average value of the gap between the silver particles. In addition, for the $\mathrm{Ag}$ film obtained at $140{ }^{\circ} \mathrm{C}$, a significant number of defects in the form of its delamination from the surface of the $\mathrm{Al}_{2} \mathrm{O}_{3}$ substrate was observed-probably, the adhesion deteriorated due to a sharp increase in the gaps between the metal particles. Thus, it can be assumed that at the first stage, films of nanoscale particles were grown on the surface of $\mathrm{Al}_{2} \mathrm{O}_{3}$ substrates, which agglomerated and enlarged at increasing temperature with the formation of microscale structures, which led to the appearance of appropriate gaps and defects in the form of delamination. 


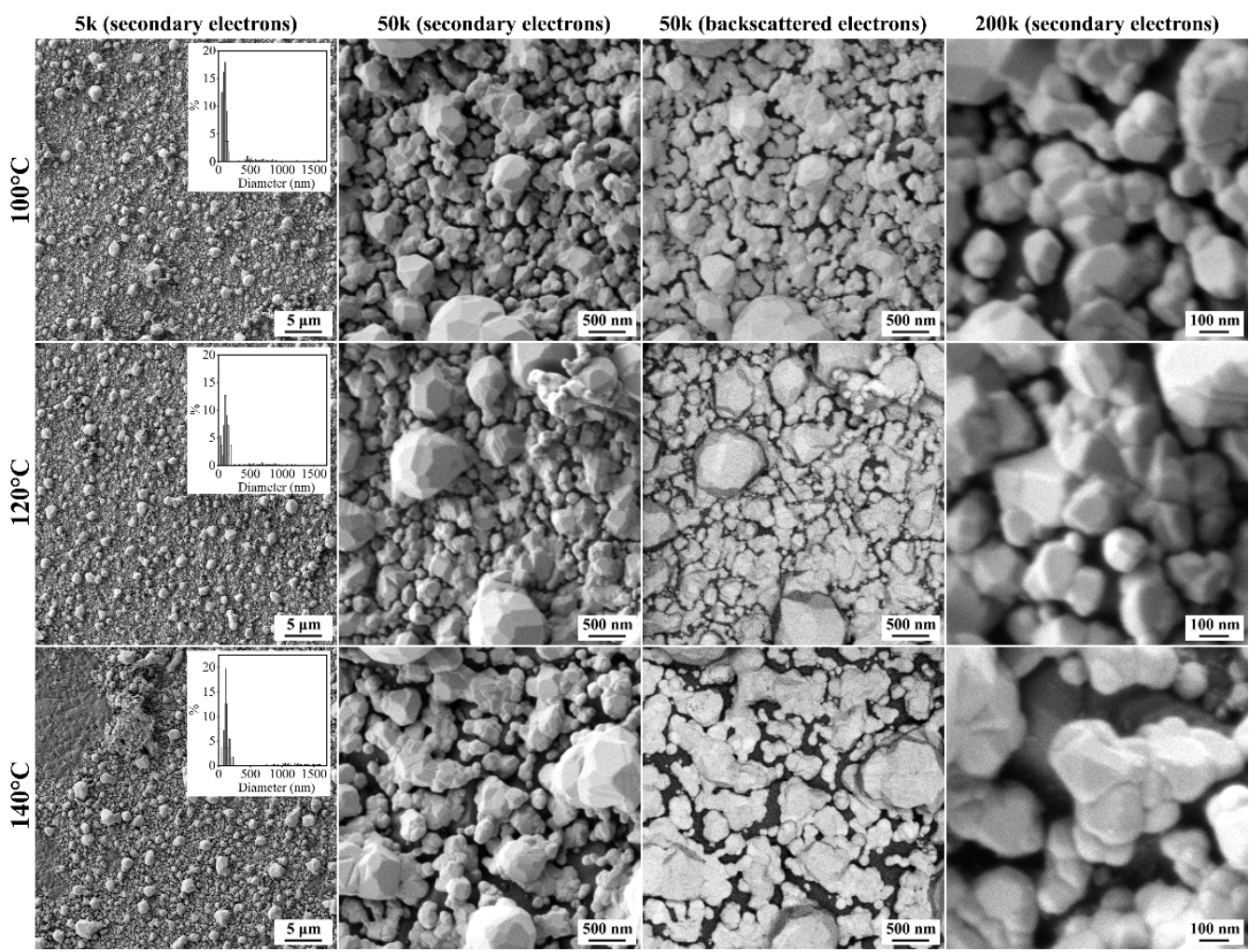

Figure 4. SEM micrographs of Ag films grown at different temperatures (using different detectors).

When studying the obtained Ag films using optical microscopy (in particular, during SERS measurements), it was discerned that there were a few dark regions with sizes of about several tens of micrometres on their surface. A more detailed study of these areas using scanning electron microscopy showed (Figure 5) that these areas were clusters of relatively small particles with an average size of about $150 \mathrm{~nm}$, organised into highly porous agglomerates.

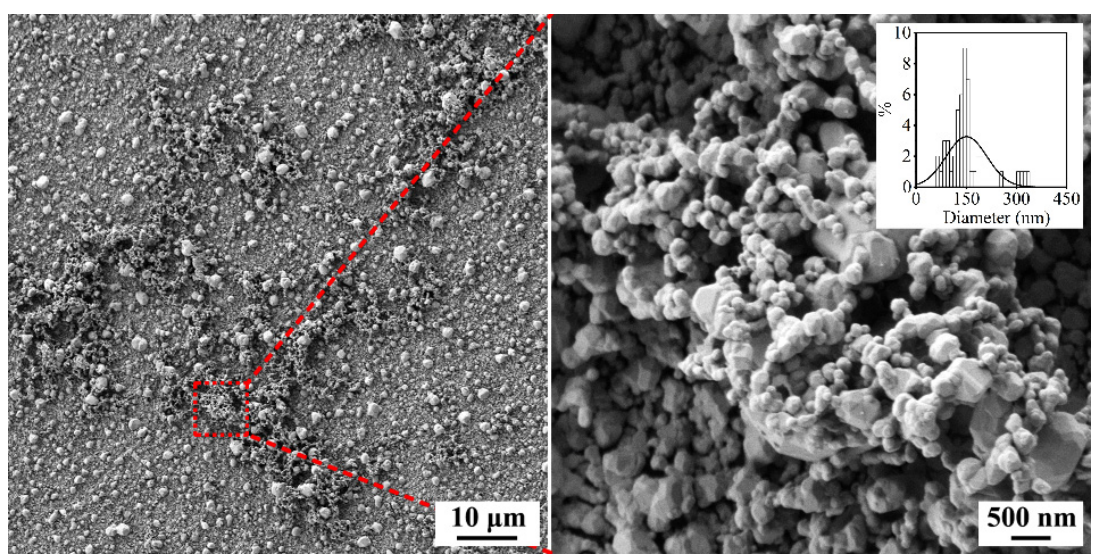

Figure 5. SEM micrographs of the dark area of the Ag-film surface grown in hydrothermal conditions at $100{ }^{\circ} \mathrm{C}$.

The microstructure of the grown Ag films was also studied using AFM in the contact and semi-contact modes. From the micrographs showing the surface topography of the materials (Figure 6), it is clear that the AFM results agree well with the SEM data. Bimodal particle size distribution was observed for all samples: both arrays of particles between 250 and $400 \mathrm{~nm}$ in size and particles from 1 micrometre and larger (but no larger than $3 \mu \mathrm{m}$ ) were observed. It can be seen that as the synthesis temperature increased, there was a 
tendency for the number of larger particles to increase. A study of the microstructure of the dark areas showed that even though there were still large particles in these areas, in the case of hydrothermal treatment temperatures of 100 and $120^{\circ} \mathrm{C}$, they were almost entirely formed by smaller particles sized 250-400 nm. However, in the case of the film grown at $140{ }^{\circ} \mathrm{C}$, a noticeable number of microsized particles were found in the dark regions, which is further evidence of the trend toward an increasing proportion of large formations with increasing synthesis temperature. Additionally, in the topographic images for the $\mathrm{Ag}$ film formed at $140{ }^{\circ} \mathrm{C}$, areas corresponding in their microstructure to the $\mathrm{Al}_{2} \mathrm{O}_{3}$ substrate were observed.
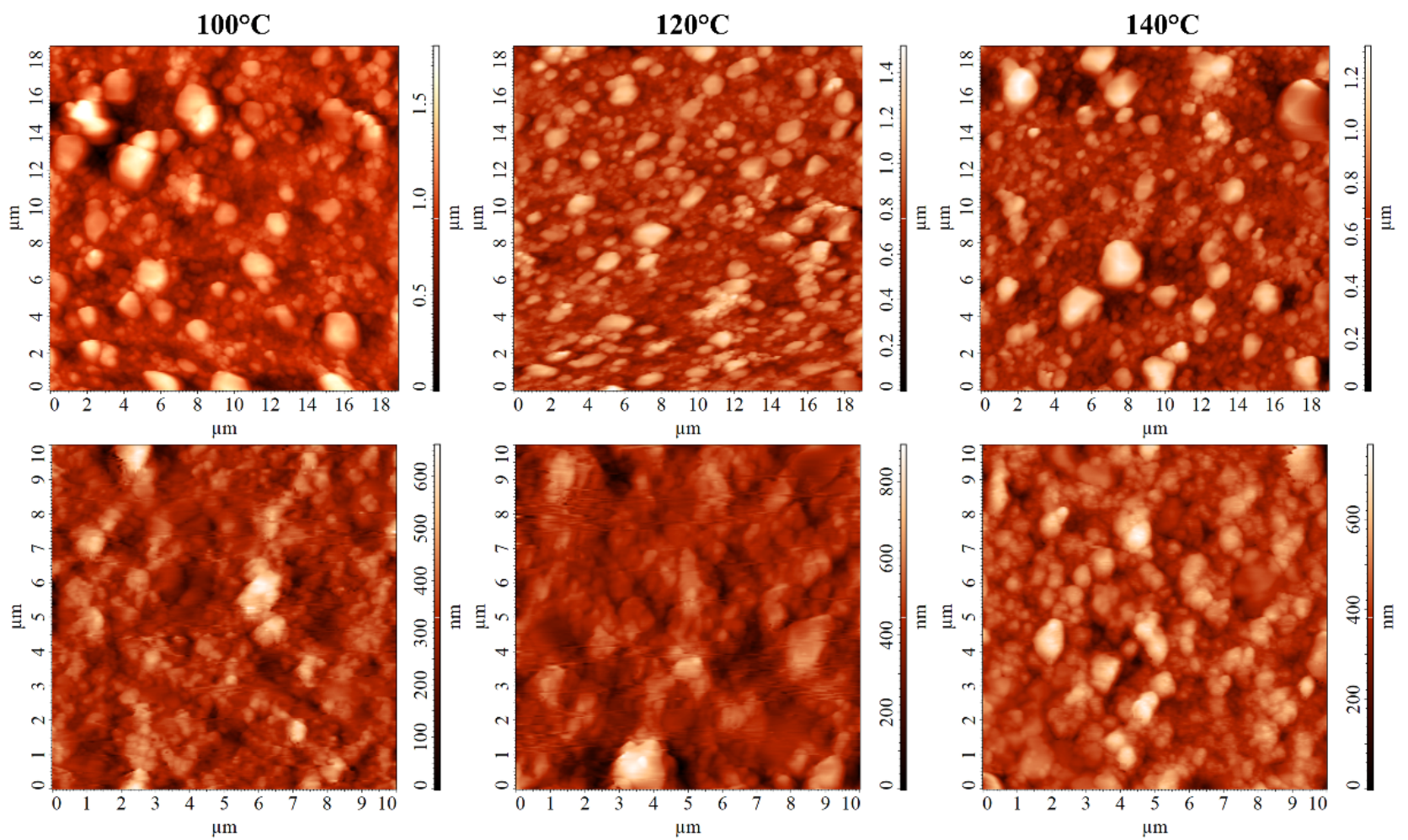

Figure 6. AFM micrographs of Ag films grown at different temperatures (top-the main surface; bottom-dark areas).

In order to study Ag particles distribution on the surface of ceramic substrates in more detail, we used scanning spreading resistance microscopy, through which a potential difference was created between the studied sample and the probe, and the intensity of the resulting current was measured. Due to the large differences in the electrophysical properties of silver and aluminium oxide, this technique makes it possible to obtain highcontrast maps of the mutual distribution of these materials. From the topographic images and maps of current distribution over the surface of the materials studied (Figure 7), it is clearly seen that an increase in the synthesis temperature led to an increase in the area of the $\mathrm{Al}_{2} \mathrm{O}_{3}$ substrate, where there were no silver particles (dark areas on the maps of current distribution). If, in the case of $\mathrm{Ag}$ film formed at $100{ }^{\circ} \mathrm{C}$, individual small areas up to $1 \mu \mathrm{m}$ long (and much less than $1 \mu \mathrm{m}^{2}$ in area) could be found, for the film grown at $120^{\circ} \mathrm{C}$, such areas were about $1-2 \mu \mathrm{m}^{2}$ in area. In the case of the film obtained in hydrothermal conditions at $140^{\circ} \mathrm{C}$, the area of regions uncovered by silver particles became higher than $10 \mu \mathrm{m}^{2}$. This confirms the tendency revealed when studying the microstructure of $\mathrm{Ag}$ films using scanning electron microscopy. In addition, typical current-voltage curves were recorded in the spreading resistance microscopy mode at the indicated points on the surface of silver coatings. It should be noted that at current strengths of about 15-20 nA, even ohmic contacts often begin to show nonlinearity, which is associated with the design features 
of the atomic force microscope. The maximum detectable current value, in this case, is $50 \mathrm{nA}$. In our case, for all investigated silver films at current strengths below $10 \mathrm{nA}$, direct dependence of current strength on voltage typical of ohmic contact was observed, and for materials obtained at temperatures of $100^{\circ} \mathrm{C}$ and $140^{\circ} \mathrm{C}$, this dependence continued to behave this way at higher currents (for Ag film obtained at $140{ }^{\circ} \mathrm{C}$, only the slope angle changed). Moreover, for this film, even in the linear section, the slope angle of the straight line was much lower than for the other samples. This fact, as well as the significantly lower value of the achieved current strength, indicates that this coating has significantly lower electrical conductivity, although it is metallic.
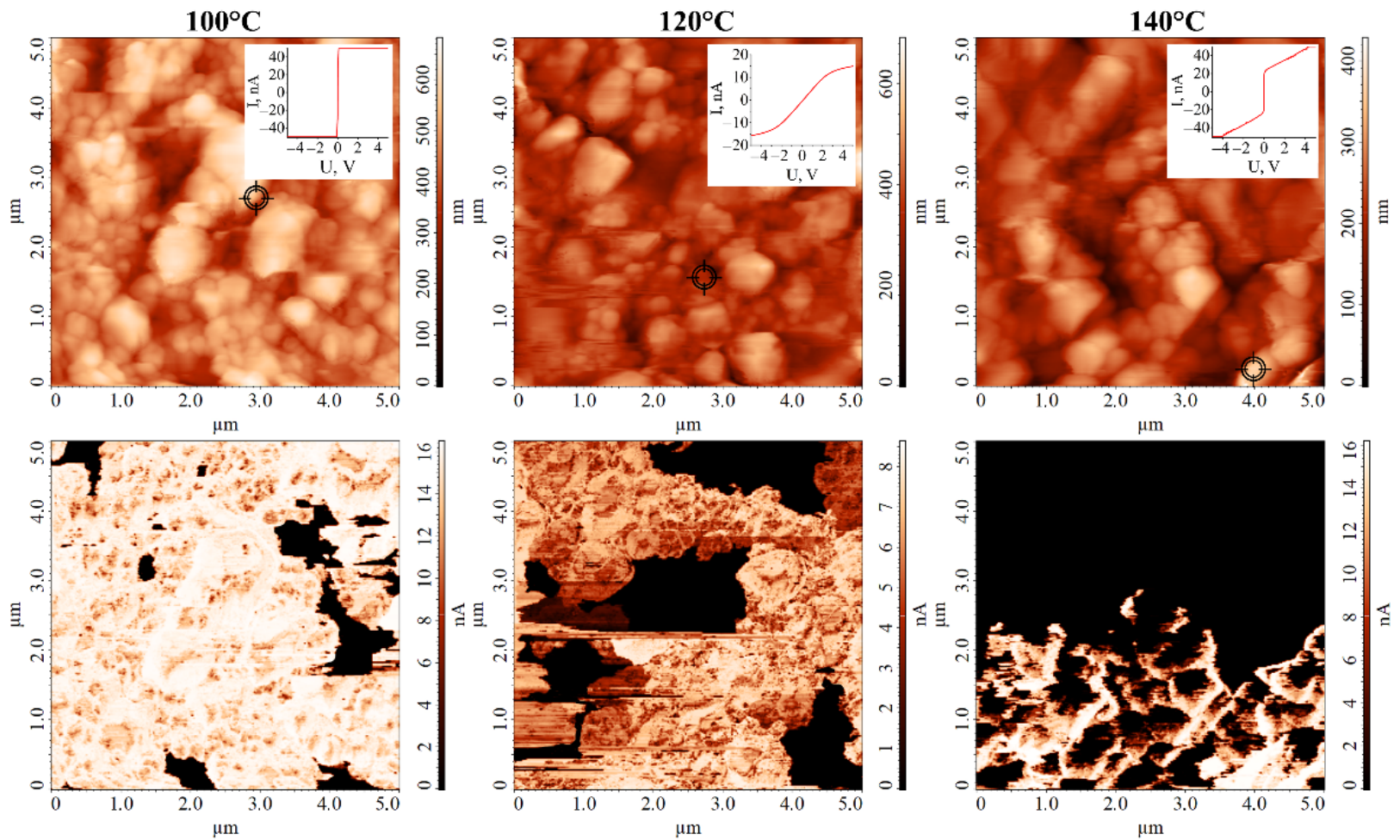

Figure 7. AFM microphotographs of Ag films grown at different temperatures (top-surface relief of the films; bottom-the corresponding current distribution maps; inset-current-voltage curves obtained at the specified points).

In addition to spreading resistance microscopy, Kelvin probe force microscopy was used to study the local electrophysical properties of the grown Ag films. From the obtained maps of the surface potential distribution (Figure 8), it can be seen that despite quite large height differences (up to $500 \mathrm{~nm}$ ) between the silver particles, the distribution of the surface charge was quite uniform. An area on the scan for the sample obtained at $140{ }^{\circ} \mathrm{C}$ was noticeable, where the surface potential was almost $200 \mathrm{mV}$ higher than for other areas on the scanned surface. Additionally, the topographic image shows that this area differed greatly in morphology from the rest of the scanned area, suggesting that it refers to the uncovered surface of the $\mathrm{Al}_{2} \mathrm{O}_{3}$ substrate, where the static charge accumulates. Using images obtained by scanning in KPFM mode, the values of electron work function were calculated to be 4.831, 4.941, and $5.015 \mathrm{eV}$ for $\mathrm{Ag}$ films grown at 100, 120, and $140{ }^{\circ} \mathrm{C}$, respectively. In all cases, the values of the electron work are higher than the reference values for silver, which can be explained by the high dispersity of metal particles. These values indicate that the intrinsic conductivity of the material may decrease with increasing synthesis temperature due to an increase in the Fermi energy. 

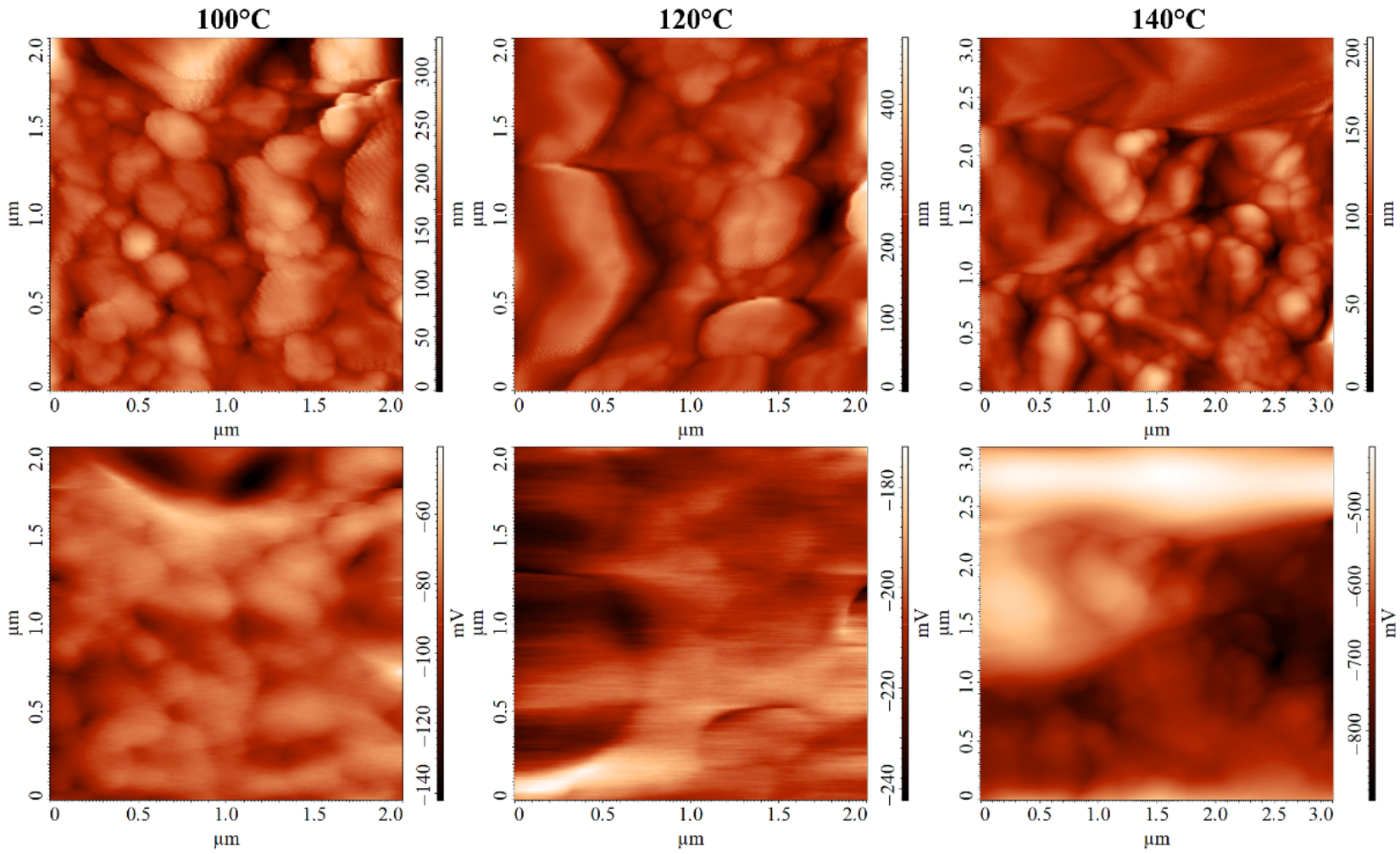

Figure 8. AFM micrographs of the surface of Ag films grown at different temperatures (top-film surface topography; bottom-the corresponding maps of surface potential distribution).

\subsection{Study of the SERS Effect When Detecting Methylene Blue}

The films formed under hydrothermal conditions were further studied for surfaceenhanced Raman scattering when detecting methylene blue. The results of preliminary measurements showed that the silver films grown at $120^{\circ} \mathrm{C}$ contained in their structure a sufficiently large number of organic components, which agrees with the results of the spreading resistance microscopy and significantly complicates their application in the detection of the analyte at low concentrations. Metal films obtained at $140^{\circ} \mathrm{C}$ were characterised by a fairly low amplification factor of the intensity of methylene blue spectral lines, which is probably due to the peculiarities of the microstructure of this material (larger particles and the presence of defects in the form of silver film delamination). At the same time, the Ag film grown at the minimum temperature $\left(100^{\circ} \mathrm{C}\right)$ in the range under consideration exhibited the most intense SERS effect. As can be seen from the Raman spectra (Figure 9a) recorded using a laser with an emission wavelength of $532 \mathrm{~nm}$, additional heat treatment of this film at $100{ }^{\circ} \mathrm{C}$ in air led to a significant reduction in the number of residual organic components contained on its surface after synthesis, washing, and drying at $50^{\circ} \mathrm{C}$. A significant enhancement of spectral lines was observed for the methylene blue applied to the Ag-film surface at a concentration of $10^{-4} \mathrm{~mol} / \mathrm{L}$ in comparison with both this substance in powder form and similar dye films on the surface of pure $\mathrm{Al}_{2} \mathrm{O}_{3}$ substrate and commercial SERS substrate. When the SERS effect was studied using a $780 \mathrm{~nm}$ laser (Figure 9b), there was also a significant increase in the intensity of spectral lines, compared with the signal from the powder and dye film on the surface of pure $\mathrm{Al}_{2} \mathrm{O}_{3}$ substrate. At the same time, the signal from the dark areas on the surface of the $\mathrm{Ag}$ film grown at $100{ }^{\circ} \mathrm{C}$ was also more intense, compared with the commercial substrate. Thus, the presence of porous clusters of small silver particles on the substrate surface led to an additional significant enhancement of the SERS effect when detecting methylene blue also using a laser with an emission wavelength of $780 \mathrm{~nm}$. 

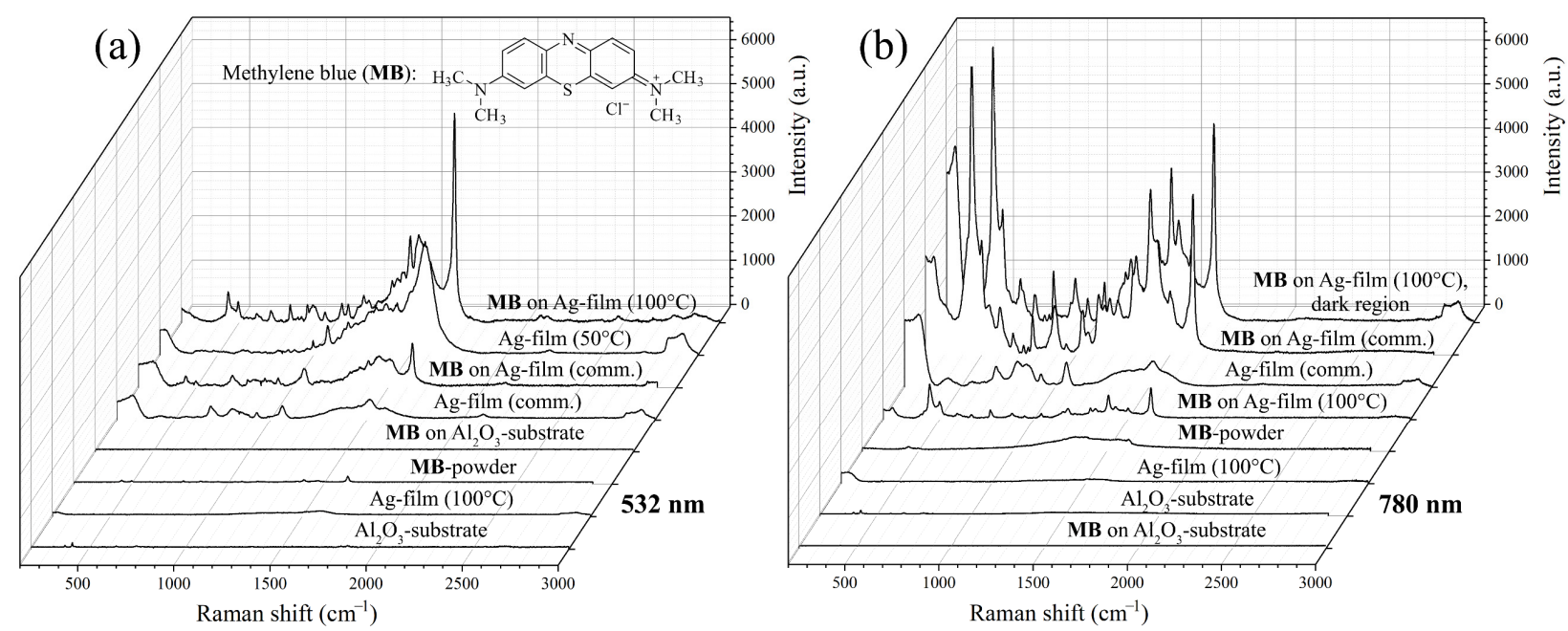

Figure 9. Raman and SERS spectra of the materials studied, obtained using lasers with an emission wavelength of 532 (a) and $780 \mathrm{~nm}$ (b); the indicated temperature values refer to the conditions of additional heat treatment of the $\mathrm{Ag}$ film in air.

Further, the Ag film formed under hydrothermal conditions at $100{ }^{\circ} \mathrm{C}$ and subjected to additional heat treatment at $100^{\circ} \mathrm{C}$ in the air was used to estimate the detection limit of methylene blue achieved through the SERS effect. For this purpose, SERS spectra of this analyte at concentrations of $10^{-4}, 10^{-5}$, and $10^{-6} \mathrm{~mol} / \mathrm{L}$ from the main surface (Figure 10a,b) and from the dark areas of the indicated silver film (Figure 10c) were obtained using lasers with different wavelengths of radiation. As can be seen from the results obtained, using a $532 \mathrm{~nm}$ laser, the minimum detection concentration of methylene blue was $10^{-5} \mathrm{~mol} / \mathrm{L}$. In contrast, when a laser with a wavelength of $780 \mathrm{~nm}$ was used, the detection limit of the indicated analyte for the main surface of the Ag film was also $10^{-5} \mathrm{~mol} / \mathrm{L}$, while for the dark areas, characterised by the presence of highly porous agglomerates of highly disperse silver particles, the minimum dye detection concentration was at $10^{-6} \mathrm{~mol} / \mathrm{L}$.
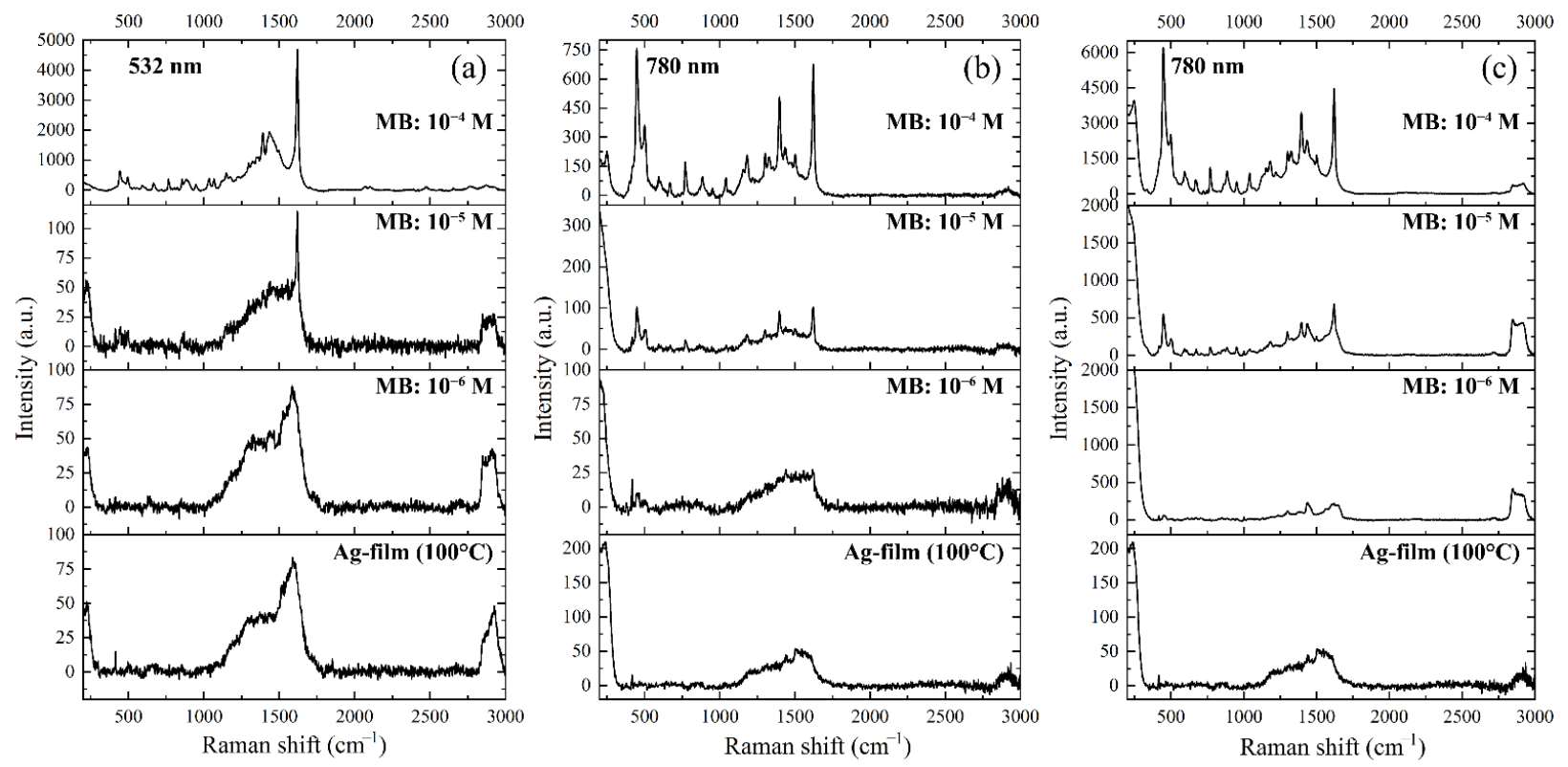

Figure 10. Raman spectra of $\mathrm{Ag}$ film (synthesis temperature- $100{ }^{\circ} \mathrm{C}$, additional heat treatment$100^{\circ} \mathrm{C}$ ) and SERS spectra of methylene blue deposited on its surface at different concentrations recorded from the main surface $(\mathbf{a}, \mathbf{b})$ and from the dark region of $\mathrm{Ag}$ film (c) using lasers with wavelengths of 532 and $780 \mathrm{~nm}$. 
Thus, the observed more intense SERS effect upon the detection of methylene blue at low concentrations for an $\mathrm{Ag}$ film grown under hydrothermal conditions at $100{ }^{\circ} \mathrm{C}$ was due to a more uniform microstructure, smaller particle and CSR sizes, and a lower content of residual organic components.

We estimated the SERS enhancement factor (EF) for the methylene blue adsorbed on particles forming dark areas of Ag films under study based on the following most widely used definition for the average SERS EF [54].

$$
\mathrm{EF}=\left(\mathrm{I}_{\mathrm{SERS}} / \mathrm{N}_{\text {surf }}\right) /\left(\mathrm{I}_{\mathrm{RS}} / \mathrm{N}_{\mathrm{vol}}\right),
$$

where ISERS and IRS are the intensities of a particular line of an analyte in the SERS and normal Raman (non-SERS) spectra measured under the same conditions, $\mathrm{N}_{\text {surf }}$ is the average number of adsorbed molecules in the scattering volume for the SERS experiment, and $\mathrm{N}_{\mathrm{vol}}$ is the average number of molecules in the scattering volume for the non-SERS experiment. In calculations, we considered spectra of methylene blue measured by using a laser with an emission wavelength of $780 \mathrm{~nm}$. To estimate the number of methylene blue molecules probed in the SERS experiment (i.e., $\mathrm{N}_{\text {surf }}$ ), the laser spot size, surface density of particles producing the enhancement, and surface density of molecules adsorbed on the metal must be known. In the performed experiments, the laser spot size was about $3.0 \mu \mathrm{m}$. Assuming the surface density of fine particles on the substrate to be about $2 \times 10^{9} \mathrm{~cm}^{-2}$ (as estimated from SEM images of dark areas), the surface density of methylene blue molecules in the monolayer to be $10^{14} \mathrm{~cm}^{-2}$ [55], and around $7 \%$ surface coverage of the metal [54], approximately $6.7 \times 10^{5}$ molecules $\left(\mathrm{N}_{\text {surf }}\right)$ were probed in the SERS experiment. For the non-SERS experiment, the number of molecules $\left(\mathrm{N}_{\mathrm{vol}}\right)$ within the probed volume of a methylene blue solution $\left(10^{-3} \mathrm{~mol} / \mathrm{L}\right)$ dispensed on an alumina substrate was estimated at $4.2 \times 10^{8}$. Substitution of $\mathrm{N}_{\text {surf }}, \mathrm{N}_{\mathrm{vol}}$, and the intensities of methylene blue line located at about $1625 \mathrm{~cm}^{-1}$ (taken from the typical SERS spectrum acquired in the dark area of Ag film and the Raman spectrum of methylene blue solution) to Equation (1) yielded an EF value equal to about $1.8 \cdot 10^{5}$.

\section{Conclusions}

A facile, one-step method of forming Ag thin-film nanostructures on the surface of $\mathrm{Al}_{2} \mathrm{O}_{3}$ substrates using a hydrothermal method was proposed. It was demonstrated that the silver films formed at $100{ }^{\circ} \mathrm{C}$ exhibited a more intense SERS effect when detecting low concentrations of methylene blue using 532 and $780 \mathrm{~nm}$ lasers, compared with both this substance in powder form and similar dye films on the surface of pure $\mathrm{Al}_{2} \mathrm{O}_{3}$ substrate and commercial SERS substrates. Using the $532 \mathrm{~nm}$ laser, the minimum detection concentration of methylene blue was $10^{-5} \mathrm{~mol} / \mathrm{L}$. In the case of the $780 \mathrm{~nm}$ laser, the detection limit of the analyte for the main surface of the $\mathrm{Ag}$ film was also $10^{-5} \mathrm{~mol} / \mathrm{L}$, and for the dark areas, whose microstructure was characterised by the presence of highly porous agglomerates of highly disperse silver particles, the minimum dye detection concentration was at $10^{-6} \mathrm{~mol} / \mathrm{L}$. It was found that under hydrothermal conditions Ag films with bimodal particle size distribution were formed. When the synthesis temperature was increased to 120 and $140{ }^{\circ} \mathrm{C}$, both an increase in the size of silver particles and the size of the gap between them were observed. The more intense SERS effect in the detection of methylene blue at low concentrations for $\mathrm{Ag}$ films grown in hydrothermal conditions at $100{ }^{\circ} \mathrm{C}$ was due to a more uniform microstructure, smaller particle and CSR sizes, as well as lower content of residual organic components. Thus, the obtained Ag thin-film nanostructures can be effectively used as SERS substrates for low concentrations detection of methylene blue and other analytes.

Author Contributions: Conceptualisation, N.P.S. and I.A.V.; methodology, A.G.M.; validation, A.A.G. and N.T.K.; formal analysis, E.P.S.; investigation, N.P.S., A.G.M., P.Y.G. and T.L.S.; resources, I.A.V. and V.G.S.; writing — original draft preparation, N.P.S. and T.L.S.; writing—review and editing, N.P.S. and V.G.S.; visualisation, N.P.S., T.L.S. and P.Y.G.; supervision, A.A.G. and N.T.K.; project administration, 
I.A.V.; funding acquisition, I.A.V. and A.A.G. All authors have read and agreed to the published version of the manuscript.

Funding: This research was funded by the Ministry of Science and Higher Education of the Russian Federation (State Contract No. 075-03-2021-095, Project Identifier 0714-2021-0007, Project Title: 'Development of functional materials with controlled electrical, chemoresistive and catalytic properties for manufacturing sensor microsystems by using methods of printed electronics').

Data Availability Statement: Not applicable.

Conflicts of Interest: The authors declare no conflict of interest.

\section{References}

1. Quan, J.; Zhang, J.; Qi, X.; Li, J.; Wang, N.; Zhu, Y. A study on the correlation between the dewetting temperature of Ag film and SERS intensity. Sci. Rep. 2017, 7, 14771. [CrossRef]

2. Gao, T.; Wang, Y.; Wang, K.; Zhang, X.; Dui, J.; Li, G.; Lou, S.; Zhou, S. Controlled Synthesis of Homogeneous Ag NanosheetAssembled Film for Effective SERS Substrate. ACS Appl. Mater. Interfaces 2013, 5, 7308-7314. [CrossRef] [PubMed]

3. Zhang, L. Self-assembly Ag nanoparticle monolayer film as SERS Substrate for pesticide detection. Appl. Surf. Sci. 2013, 270, 292-294. [CrossRef]

4. Zhao, H.-Z.; Xu, Y.; Wang, C.-Y.; Wang, R.; Xiang, S.-T.; Chen, L. Design and fabrication of a microfluidic SERS chip with integrated Ag film@nanoAu. RSC Adv. 2016, 6, 14105-14111. [CrossRef]

5. Semin, D.J.; Rowlen, K.L. Influence of vapor deposition parameters on SERS active Ag film morphology and optical properties. Anal. Chem. 1994, 66, 4324-4331. [CrossRef]

6. Yang, C.; Qin, Y.; Zhu, X.; Yin, M.; Li, D.; Chen, X.; Song, Y. Inverted nanotaper-based Ag film for optical absorption and SERS applications. J. Alloys Compd. 2015, 632, 634-638. [CrossRef]

7. Nikov, R.G.; Nedyalkov, N.N.; Atanasov, P.A.; Grochowska, K.; Iwulska, A.; Sliwinski, G. Laser nanostructuring of Au/Ag and $\mathrm{Au} / \mathrm{Ni}$ films for application in SERS. In Proceedings of the Seventeenth International School on Quantum Electronics: Laser Physics and Applications, Sofia, Bulgaria, 24-28 September 2013; p. 87700D.

8. Baibarac, M.; Cochet, M.; Łapkowski, M.; Mihut, L.; Lefrant, S.; Baltog, I. SERS spectra of polyaniline thin films deposited on rough Ag, Au and Cu. Polymer film thickness and roughness parameter dependence of SERS spectra. Synth. Met. 1998, 96, 63-70. [CrossRef]

9. Wang, Y.; Song, W.; Ruan, W.; Yang, J.; Zhao, B.; Lombardi, J.R. SERS Spectroscopy Used To Study an Adsorbate on a Nanoscale Thin Film of CuO Coated with Ag. J. Phys. Chem. C 2009, 113, 8065-8069. [CrossRef]

10. Shao, Q.; Zhang, D.; Wang, C.; Tang, Z.; Zou, M.; Yang, X.; Gong, H.; Yu, Z.; Jin, S.; Liang, P. Ag@MIL-101(Cr) Film Substrate with High SERS Enhancement Effect and Uniformity. J. Phys. Chem. C 2021, 125, 7297-7304. [CrossRef]

11. Huang, Y.; Sun, L.; Xie, K.; Lai, Y.; Liu, B.; Ren, B.; Lin, C. SERS study of Ag nanoparticles electrodeposited on patterned TiO 2 nanotube films. J. Raman Spectrosc. 2011, 42, 986-991. [CrossRef]

12. Dai, Q.; Li, L.; Wang, C.; Lv, C.; Su, Z.; Chai, F. Fabrication of a Flowerlike Ag Microsphere Film with Applications in Catalysis and as a SERS Substrate. Eur. J. Inorg. Chem. 2018, 2018, 2835-2840. [CrossRef]

13. Li, L.; Chin, W.S. Rapid Fabrication of a Flexible and Transparent Ag Nanocubes@PDMS Film as a SERS Substrate with High Performance. ACS Appl. Mater. Interfaces 2020, 12, 37538-37548. [CrossRef]

14. Zhang, Z.; Yu, J.; Yang, J.; Lv, X.; Wang, T. Preparation of sensitive and recyclable porous Ag/ $\mathrm{TiO}_{2}$ composite films for SERS detection. Appl. Surf. Sci. 2015, 359, 853-859. [CrossRef]

15. Niu, Z.; Zhou, C.; Wang, J.; Xu, Y.; Gu, C.; Jiang, T.; Zeng, S.; Zhang, Y.; Ang, D.S.; Zhou, J. UV-light-assisted preparation of $\mathrm{MoO}_{3}-\mathrm{x} / \mathrm{Ag}$ NPs film and investigation on the SERS performance. J. Mater. Sci. 2020, 55, 8868-8880. [CrossRef]

16. Yuan, J.; Lai, Y.; Duan, J.; Zhao, Q.; Zhan, J. Synthesis of a $\beta$-cyclodextrin-modified Ag film by the galvanic displacement on copper foil for SERS detection of PCBs. J. Colloid Interface Sci. 2012, 365, 122-126. [CrossRef]

17. Rao, V.K.; Radhakrishnan, T.P. Tuning the SERS Response with Ag-Au Nanoparticle-Embedded Polymer Thin Film Substrates. ACS Appl. Mater. Interfaces 2015, 7, 12767-12773. [CrossRef]

18. Huang, X.X.; Sun, H.L.; Wang, G.X.; Stock, H.R. Self-formation of Ag particles/Ag-Zr alloy films on flexible polyimide as SERS substrates. Appl. Surf. Sci. 2019, 487, 1341-1347. [CrossRef]

19. Lian, X.; Sun, H.; Lv, Y.; Wang, G. Room temperature self-assembled Ag nanoparticles/Mo-37.5\% Ag film as efficient flexible SERS substrate. Mater. Lett. 2020, 275, 128164. [CrossRef]

20. Zhang, Z.; Yu, J.; Ma, L.; Sun, Y.; Wang, P.; Wang, T.; Peng, S. Preparation of the plasmonic Ag/AgBr/ZnO film substrate for reusable SERS detection: Implication to the Z-scheme photocatalytic mechanism. Spectrochim. Acta Part A Mol. Biomol. Spectrosc. 2020, 224, 117381. [CrossRef]

21. Liu, Z.; Hu, R.; Yu, J.; Wang, R.; Cheng, J.; Huo, M.; Wu, T.; Li, L. Fabrication of ZnO interface layer from a novel aqueous sol-gel precursor solution for organic solar cells. Synth. Met. 2021, 274, 116737. [CrossRef]

22. Sivashanmugan, K.; Liao, J.-D.; Liu, B.H.; Yao, C.-K.; Luo, S.-C. Ag nanoclusters on ZnO nanodome array as hybrid SERS-active substrate for trace detection of malachite green. Sens. Actuators B Chem. 2015, 207, 430-436. [CrossRef] 
23. Sun, L.; Zhao, D.; Ding, M.; Zhao, H.; Zhang, Z.; Li, B.; Shen, D. A white-emitting ZnO-Au nanocomposite and its SERS applications. Appl. Surf. Sci. 2012, 258, 7813-7819. [CrossRef]

24. Zhou, M.; Liu, X.; Yu, B.; Cai, J.; Liao, C.; Ni, Z.; Zhang, Z.; Ren, Z.; Bai, J.; Fan, H. MnO $/$ Au hybrid nanowall film for high-performance surface-enhanced Raman scattering substrate. Appl. Surf. Sci. 2015, 333, 78-85. [CrossRef]

25. Lee, H.; Liao, J.-D.; Sivashanmugan, K.; Liu, B.; Fu, W.; Chen, C.-C.; Chen, G.; Juang, Y.-D. Gold Nanoparticle-Coated ZrO ${ }_{2}^{-}$ Nanofiber Surface as a SERS-Active Substrate for Trace Detection of Pesticide Residue. Nanomaterials 2018, 8, 402. [CrossRef]

26. Kavitha, C.; Bramhaiah, K.; John, N.S.; Ramachandran, B.E. Low cost, ultra-thin films of reduced graphene oxide-Ag nanoparticle hybrids as SERS based excellent dye sensors. Chem. Phys. Lett. 2015, 629, 81-86. [CrossRef]

27. Yan, B.; Li, K.; Gu, P.; Li, Z.; Tang, C.; Liu, F.; Zhan, P.; Sui, C.; Wang, Z. Thermal stability of ultrathin and high dielectric ta-C films coated with Ag nanostructures for SERS. J. Raman Spectrosc. 2018, 49, 431-437. [CrossRef]

28. Zheng, G.; Zhang, P.; Zhang, S.; Peng, Y.; Huang, L.; Zhang, L.; Jin, Y.; Jiao, Z.; Sun, X. SERS effect of selectively adsorbed dyes by hydrothermally-produced $\mathrm{MoS}_{2}$ nanosheets. New J. Chem. 2018, 42, 18906-18912. [CrossRef]

29. He, Y.; Han, X.; Chen, D.; Kang, L.; Jin, W.; Qiang, R.; Xu, P.; Du, Y. Chemical deposition of Ag nanostructures on polypyrrole films as active SERS substrates. RSC Adv. 2014, 4, 7202. [CrossRef]

30. Li, Z.; Meng, G.; Huang, Q.; Hu, X.; He, X.; Tang, H.; Wang, Z.; Li, F. Ag Nanoparticle-Grafted PAN-Nanohump Array Films with 3D High-Density Hot Spots as Flexible and Reliable SERS Substrates. Small 2015, 11, 5452-5459. [CrossRef]

31. Duan, H.; Wang, D.; Kurth, D.G.; Möhwald, H. Directing Self-Assembly of Nanoparticles at Water/Oil Interfaces. Angezw. Chem. Int. Ed. 2004, 43, 5639-5642. [CrossRef]

32. Rajesh, D.; Mahendar, M.; Sunandana, C.S. Effect of Etching on the Optical, Morphological Properties of Ag Thin Films for SERS Active Substrates. J. Chem. 2013, 2013, 1-5. [CrossRef]

33. Ming, T.; Kou, X.; Chen, H.; Wang, T.; Tam, H.-L.; Cheah, K.-W.; Chen, J.-Y.; Wang, J. Ordered Gold Nanostructure Assemblies Formed By Droplet Evaporation. Angew. Chem. Int. Ed. 2008, 47, 9685-9690. [CrossRef]

34. Rajkumar, K.; Jayram, N.D.; Mangalaraj, D.; Rajendra Kumar, R.T. One step 'dip' and 'use' Ag nanostructured thin films for ultrahigh sensitive SERS Detection. Mater. Sci. Eng. C 2016, 68, 831-836. [CrossRef]

35. Liu, J.-W.; Zhu, J.-H.; Zhang, C.-L.; Liang, H.-W.; Yu, S.-H. Mesostructured Assemblies of Ultrathin Superlong Tellurium Nanowires and Their Photoconductivity. J. Am. Chem. Soc. 2010, 132, 8945-8952. [CrossRef]

36. Malaquin, L.; Kraus, T.; Schmid, H.; Delamarche, E.; Wolf, H. Controlled Particle Placement through Convective and Capillary Assembly. Langmuir 2007, 23, 11513-11521. [CrossRef]

37. Li, R.; Yang, J.; Han, J.; Liu, J.; Huang, M. Quantitative determination of melamine in milk using Ag nanoparticle monolayer film as SERS substrate. Phys. E Low-Dimens. Syst. Nano. 2017, 88, 164-168. [CrossRef]

38. Srivastava, S.; Kotov, N.A. Composite Layer-by-Layer (LBL) Assembly with Inorganic Nanoparticles and Nanowires. Acc. Chem. Res. 2008, 41, 1831-1841. [CrossRef] [PubMed]

39. Leverette, C.L.; Villa-Aleman, E.; Jokela, S.; Zhang, Z.; Liu, Y.; Zhao, Y.; Smith, S.A. Trace detection and differentiation of uranyl(VI) ion cast films utilizing aligned Ag nanorod SERS substrates. Vib. Spectrosc. 2009, 50, 143-151. [CrossRef]

40. Coe-Sullivan, S.; Steckel, J.S.; Woo, W.-K.; Bawendi, M.G.; Bulović, V. Large-Area Ordered Quantum-Dot Monolayers via Phase Separation During Spin-Casting. Adv. Funct. Mater. 2005, 15, 1117-1124. [CrossRef]

41. Egorova, T.L.; Kalinina, M.V.; Simonenko, E.P.; Simonenko, N.P.; Shilova, O.A.; Sevastyanov, V.G.; Kuznetsov, N.T. Liquid-phase synthesis and physicochemical properties of xerogels, nanopowders and thin films of the $\mathrm{CeO}_{2}-\mathrm{Y}_{2} \mathrm{O}_{3}$ system. Russ. J. Inorg. Chem. 2016, 61, 1061-1069. [CrossRef]

42. Egorova, T.L.; Kalinina, M.V.; Simonenko, E.P.; Simonenko, N.P.; Kopitsa, G.P.; Glumov, O.V.; Mel'nikova, N.A.; Murin, I.V.; Almásy, L.; Shilova, O.A. Study of the effect of methods for liquid-phase synthesis of nanopowders on the structure and physicochemical properties of ceramics in the $\mathrm{CeO}_{2}-\mathrm{Y}_{2} \mathrm{O}_{3}$ system. Russ. J. Inorg. Chem. 2017, 62, 1275-1285. [CrossRef]

43. Kalinina, M.V.; Morozova, L.V.; Egorova, T.L.; Arsent'ev, M.Y.; Drozdova, I.A.; Shilova, O.A. Synthesis and physicochemical properties of a solid oxide nanocomposite based on a $\mathrm{ZrO}_{2}-\mathrm{Y}_{2} \mathrm{O}_{3}-\mathrm{Gd}_{2} \mathrm{O}_{3}-\mathrm{MgO}$ system. Glas. Phys. Chem. 2016, 42, 505-511. [CrossRef]

44. Zhu, C.; Meng, G.; Huang, Q.; Huang, Z. Vertically aligned Ag nanoplate-assembled film as a sensitive and reproducible SERS substrate for the detection of PCB-77. J. Hazard. Mater. 2012, 211-212, 389-395. [CrossRef]

45. Ji, R.; Sun, W.; Chu, Y. One-step hydrothermal synthesis of $\mathrm{Ag} / \mathrm{Cu}_{2} \mathrm{O}$ heterogeneous nanostructures over $\mathrm{Cu}$ foil and their SERS applications. RSC Adv. 2014, 4, 6055. [CrossRef]

46. Yang, L.; Wang, W.; Jiang, H.; Zhang, Q.; Shan, H.; Zhang, M.; Zhu, K.; Lv, J.; He, G.; Sun, Z. Improved SERS performance of single-crystalline $\mathrm{TiO}_{2}$ nanosheet arrays with coexposed $\{001\}$ and $\{101\}$ facets decorated with Ag nanoparticles. Sens. Actuators $B$ Chem. 2017, 242, 932-939. [CrossRef]

47. Simonenko, T.L.; Bocharova, V.A.; Simonenko, N.P.; Gorobtsov, F.Y.; Simonenko, E.P.; Muradova, A.G.; Sevastyanov, V.G.; Kuznetsov, N.T. Formation of One-Dimensional Hierarchical $\mathrm{MoO}_{3}$ Nanostructures under Hydrothermal Conditions. Russ. J. Inorg. Chem. 2020, 65, 459-465. [CrossRef]

48. Li, D.; Wu, S.; Wang, Q.; Wu, Y.; Peng, W.; Pan, L. Ag@C Core-Shell Colloidal Nanoparticles Prepared by the Hydrothermal Route and the Low Temperature Heating-Stirring Method and Their Application in Surface Enhanced Raman Scattering. J. Phys. Chem. C 2012, 116, 12283-12294. [CrossRef] 
49. Zhang, Y.; Xing, C.; Jiang, D.; Chen, M. Facile synthesis of core-shell-satellite Ag/C/Ag nanocomposites using carbon nanodots as reductant and their SERS properties. CrystEngComm 2013, 15, 6305. [CrossRef]

50. Jiang, T.; Wang, X.; Zhou, J.; Chen, D.; Zhao, Z. Hydrothermal synthesis of Ag@MSiO $@$ @Ag three core-shell nanoparticles and their sensitive and stable SERS properties. Nanoscale 2016, 8, 4908-4914. [CrossRef]

51. Chang, S.; Ruan, S.; Wu, E.; Huang, W. $\mathrm{CeO}_{2}$ Thickness-Dependent SERS and Catalytic Properties of CeO ${ }_{2}$-on-Ag Particles Synthesized by $\mathrm{O}_{2}$-Assisted Hydrothermal Method. J. Phys. Chem. C 2014, 118, 19238-19245. [CrossRef]

52. Volkov, I.A.; Simonenko, N.P.; Efimov, A.A.; Simonenko, T.L.; Vlasov, I.S.; Borisov, V.I.; Arsenov, P.V.; Lebedinskii, Y.Y.; Markeev, A.M.; Lizunova, A.A.; et al. Platinum Based Nanoparticles Produced by a Pulsed Spark Discharge as a Promising Material for Gas Sensors. Appl. Sci. 2021, 11, 526. [CrossRef]

53. Gorobtsov, P.Y.; Fisenko, N.A.; Solovey, V.R.; Simonenko, N.P.; Simonenko, E.P.; Volkov, I.A.; Sevastyanov, V.G.; Kuznetsov, N.T. Microstructure and local electrophysical properties of sol-gel derived $\left(\mathrm{In}_{2} \mathrm{O}_{3}-10 \% \mathrm{SnO}_{2}\right) / \mathrm{V}_{2} \mathrm{O}_{5}$ films. Colloid Interface Sci. Commun. 2021, 43, 100452. [CrossRef]

54. Le Ru, E.C.; Blackie, E.; Meyer, M.; Etchegoin, P.G. Surface Enhanced Raman Scattering Enhancement Factors: A Comprehensive Study. J. Phys. Chem. C 2007, 111, 13794-13803. [CrossRef]

55. Kipling, J.J.; Wilson, R.B. Adsorption of methylene blue in the determination of surface areas. J. Appl. Chem. 2007, 10, 109-113. [CrossRef] 